\title{
Northern Ontario School of Medicine opens
}

Canada's first new medical school in 30 years, the Northern Ontario School of Medicine opens its doors Sept. 6 with an entry class of 56 students and an innovative model of medical training.

Four years and $\$ 95.3$ million in the making, the school (www.normed.ca/) was created to alleviate the chronic shortage of physicians in Northern Ontario.

In keeping with that mission, the admissions process gives preference to applicants who have lived in Northern Ontario, said Dr. Jill Konkin, associate dean of admissions and student affairs. "The evidence shows that people who come from rural and remote communities are more likely to go back to similar-sized communities."

About $70 \%$ of those accepted have lived 10 years or more in
Northern Ontario, said Konkin. About 18\% are Francophone, $17 \%$ are bilingual and $12.5 \%$ are Aboriginal.

The curriculum emphasizes Northern rural and remote clinical practice. Third-year students will work for 8 months with family physicians in these communities, rather than completing clinical rotations at teaching hospitals.

"The students cover the major disciplines just like in other schools but from the family practice view of the world, living in the community and becoming part of a health team," said Dean Roger Strasser. Many of the school's 350 faculty members are doctors working in rural Northern communities.

This community-based medical-education model was pioneered by Flinders University in
Australia. Several US medical schools and BC's Northern Medical Program use similar models.

The new school will rely heavily on electronic communications methods to connect students who are divided between 2 campuses: 32 are enrolled at Sudbury's Laurentian University and 24 at Lakehead University in Thunder Bay. Videoconferencing facilities will be used to deliver lectures simultaneously to students at both campuses, and Web-based technologies will deliver case-based exercises to students and keep them connected to one another even when they are working in remote communities.

"The school is still a work in progress," Strasser said. Rosanna Tamburri, Oakville, Ont.

\section{Federal Regulations}

\section{New medicinal marijuana rules ease onus on physicians}

Revised regulations governing Health Canada's medicinal marijuana program reduce the onus on physicians as gatekeepers, but the 4-year-old program is still cause for concern, says the CMA.

Under the revised Marihuana Medical Access Regulations, which came into effect June 29, physicians no longer have to make a risk-benefit declaration or recommend daily dosages.

Instead, applicants must acknowledge that the benefits and risks are not "fully understood" and that they accept those risks. Applicants also recommend their own dosage and route of administration, which the physician notes in his or her declaration.

Physicians must also state which of 2 categories (down from 3 ) the patient falls under (end-oflife or debilitating symptom) and that conventional treatments are inappropriate or ineffective.

CMA's Chief Medical Officer says that while this is a "more acceptable" approach, the CMA is still "fundamentally opposed because of the lack of [scientific] evidence. Physicians should not be gatekeepers to an unproven product," says Dr. Isra Levy.

"It's challenging," says Valerie Lasher, manager of Health Canada's Marihuana Access Division. "We don't have the research we need to make this an approved drug." The program is "evolving," she says.

The revised regulations also allow for a pilot project involving pharmacists who will distribute government-grown marijuana. Currently, the legal means of obtaining marijuana: are to get a government permit to grow it yourself or assign a grower, or to access the government supply via home delivery or a physician's office. Lasher says only 1 or 2 Canadian physicians now distribute marijuana.

"We want to move the program to a primary care model which includes distribution through pharmacies," says
Lasher. The pilot is expected to be complete by 2007 .

The regulations also make it "reasonably clear that it's okay for doctors to refuse to participate," says Levy.

Such clarity is desirable given that at least 1 college has brokered a complaint. In 2002, a patient complained to the Ontario college when his physician refused to prescribe marijuana (Members' Dialogue, March/April 2002:19-20). The college decided the physician was justified. "The issue of what constitutes the appropriate use of marijuana for medical purposes is still somewhat unsettled," wrote the committee, which advised physicians to "tread carefully." Barbara Sibbald, CMAJ

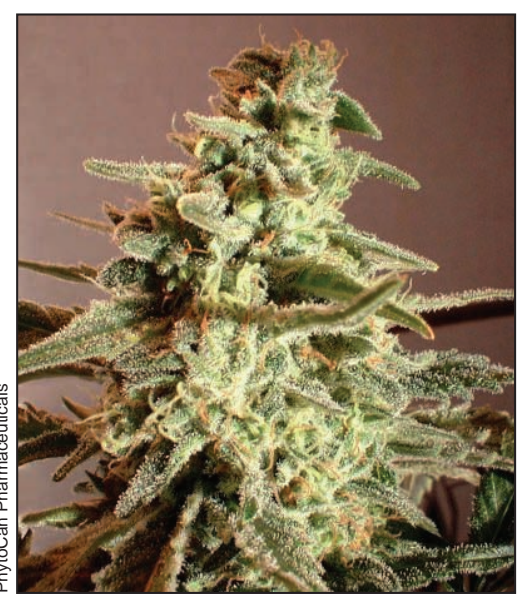

Canada's approach to medicinal marijuana is evolving. 